Ibrahim Card Med J 2011;1(1):36-40

\title{
Role of Plasma B-type Natriuretic Peptide in Diagnosing Heart Failure
}

\author{
Mohammed Safiul Alam, ${ }^{1}$ KHMS Sirajul Haque, ${ }^{2}$ Md. Nurul Amin ${ }^{3}$
}

\begin{abstract}
Background: Urgent diagnosis of heart failure is of immense practical significance to the cardiologists to decide the need of intensive coronary care. ECG, echocardiography and chest skiagram could diagnose heart failure with fair degree of accuracy. However, these facilities are not available in every hospital and time consuming. That purpose an inexpensive, easily interpretable diagnostic tool is a pressing need to diagnose heart failure. Recently plasma B-Type natriuretic peptide (BNP) has been identified as a cardiac marker specifically secreted from the ventricles in response to stretching of cardiac muscles. This case-control study was carried out to find the role of plasma BNP in diagnosing heart failure and its severity.
\end{abstract}

Patients \& Methods: The study was conducted in the Department of Cardiology, BSMMU, Dhaka on 120 subjects - 78 patients of established heart failure (case) and 42 patients of chronic obstructive pulmonary disease and chronic asthma (control). On the basis of ejection fraction they were grouped into systolic heart failure (LVEF $<45 \%$ ) and non-systolic heart failure (LVEF $>45 \%)$. ECG, chest X-ray and echocardiography were done to find out the cause and severity of heart failure. B-type natriuretic peptide at a cut-off value of $>100 \mathrm{pg} / \mathrm{ml}$ was used to find its accuracy in diagnosing heart failure and its severity.

Result: Approximately $57.7 \%$ of the established cases of heart failure and $64.3 \%$ of the controls were over 50 years old. Over $70 \%$ of both cases and control was male with male to female ratio being roughly $3: 1$. More than $60 \%$ of the cases belonged to NYHA classIV followed by $28.2 \%$ to Class-III, $10.3 \%$ to Class-II and only $1.3 \%$ to Class-I. Nearly $95 \%$ of the cases had plasma BNP $>100$ $\mathrm{pg} / \mathrm{ml}$, while over $90 \%$ of the controls had plasma BNP 100 or below $100 \mathrm{pg} / \mathrm{ml}$. The heart failure was significantly associated with raised plasma BNP level $(\mathrm{p}<0.001)$. The plasma BNP was also found to increase significantly with the severity of heart failure $(\mathrm{p}<$ 0.001). The mean plasma BNP was observed to be staggeringly raised among the systolic heart failure patients $(978.38 \mathrm{pg} / \mathrm{ml})$ than that among non-systolic heart failure patients $(390.68 \mathrm{pg} / \mathrm{ml})$

$(\mathrm{p}<0.001$ ). The sensitivity of plasma BNP (at cut off value of $100 \mathrm{pg} / \mathrm{ml}$ ) in correctly diagnosing heart failure was $93.6 \%$, while the specificity of the test in differentiating those who do not have heart failure was $90.5 \%$. The positive and negative predictive values (PPVs and NPVs) of the test were $94.8 \%$ and $88.4 \%$ respectively. The overall diagnostic accuracy was appreciably high (92.5\%).

Conclusion: The study concludes that B-type natriuretic peptide might be a promising cardiac marker for diagnosis of heart failure and its severity.

\section{Introduction}

Congestive heart failure (CHF) is a common clinical disorder, estimated to affect more than 2 million patients in the United States. About 400,000 new patients develop congestive heart failure each year. Mortality and morbidity rates are high. Approximately 900,000 patients require hospitalization annually and up to 200,000 patients die from this condition. ${ }^{1}$ In developing countries like Bangladesh, with the increase of life expectancy and shifting from traditional life-style, cardiovascular disease as well as mortality caused by it is showing an increasing trend. ${ }^{2}$

Due to improvement in diagnosis and therapy with acute coronary syndrome, more patients are now surviving myocardial infarction than in previous decades. As a consequence the incidence of heart failure has dramatically increased. ${ }^{3}$ Other major causes of heart failure include dilated cardiomyopathy, valvular heart disease, hypertension, congenital heart disease, corpulmonalae etc. However, other critical illnesses like chronic obstructive pulmonary disease, pulmonary embolism and pneumonia may mimic acute $\mathrm{CHF}^{4}$

Heart failure is often difficult to diagnose in the emergency department or urgent care setting as the symptoms may be non specific and physical findings are not sensitive enough to be used as a basis for an accurate diagnosis. Although echocardiography is considered the gold standard for the detection of left ventricular dysfunction, it is not always easily accessible and may not reflect an acute condition. Besides these, many patients are very ill and may have difficulties in lying still. A considerable number of patients are dyspnoeic, obese or have COPD which may reduce $x$-ray image quality.

Clinical information obtained from ECG, chest x-ray and echocardiography may provide valuable clue but these facilities are not always accessible in every level of health

\footnotetext{
Authors' Information

${ }^{1}$ Dr. Mohammed Safiul Alam, MBBS, MD (Cardiology); Asst. Professor, Dept. of Cardiology, Chittagong Medical College, Chittagong, Bangladesh.

2 Prof. KHMS Sirajul Haque, MBBS,FCPS,FRCP (Edin) FACC, Professor (Cardiology), University Cardiac Centre, Bangobandhu Sheikh Mujib Medical University, Dhaka, Bangladesh

${ }^{3}$ Dr. Nurul Amin, MBBS; DMCH, MPhil (P SM), MPH (Thailand), Research Specialist, ICHRI, Dhaka

Correspondence: Dr. Mohammed Safiul Alam, Mob.: 01715-059716,E-mail: safichowdhuy@yahoo.co.uk
} 
care facilities. Therefore, an inexpensive, widely available and easily interpretable diagnostic tool is essential to diagnose heart failure irrespective of underlying etiology and pathology. B-Type natriuretic peptide (BNP) is a cardiac neurohormone specifically secreted from the ventricles in response to volume expansion and pressure overload. It is a 32 amino acid protein whose level is detectably elevated in the majority of patient with acute congestive heart failure. ${ }^{4}$

BNP has significant independent predictive power to other clinical variables to diagnose congestive heart failure. $^{3}$ Increased BNP is also a prognostic marker of heart failure. ${ }^{5}$ Level of B-type natriuretic peptide is elevated in patients with left ventricular dysfunction and correlate with the New York heart association class II. The diagnostic accuracy of BNP at cut off of $100 \mathrm{pg}$ per milliliters is 83.4 percent. $^{3}$ Levels of BNP correlate with the prognosis of heart failure. Measurement of serum BNP is, therefore, useful in assessing the status of patients with decompensated congestive heart failure. ${ }^{6}$

B-type natriuretic peptide with a cut off value of $100 \mathrm{pg}$ per milliliter had sensitivity of 90 percent, a specificity of 76 percent and an accuracy of 83 percent for differentiating congestive heart failure from other causes of dyspnoea. ${ }^{3}$ The value of BNP has already been recognized by their inclusion in the recent European guideline for the diagnosis of chronic heart failure. ${ }^{7}$ For the last few years BNP has been emerging as a reliable marker of heart failure and is used as a rapid tool for the diagnosis of heart failure. However BNP level can only be measured in a specialized laboratory which has hampered its use on daily practice. Many studies with BNP have been done in different parts of the world. The present study has been designed to assess the diagnostic accuracy of plasma BNP in patients of acute and chronic heart failure and also to find the association between plasma BNP level and severity of heart failure.

\section{Patients \& Methods}

The present cross-sectional case-control study was carried out in the Department of Cardiology, Bangabandhu Sheikh Mujib Medical University, Dhaka between July 2004 to June 2006. Patients of acute and chronic heart failure admitted in the above mentioned hospital were the cases, while patients of COPD and asthma were taken as controls. A total of 78 cases (patients of heart failure) and 42 controls were included in the study. The cases comprised of ischemic heart disease $(n=46)$, dilated cardiomyopathy $(\mathrm{n}=16)$, valvular heart disease $(\mathrm{n}=8)$, hypertensive heart failure $(n=6)$ and shunt anomaly $(n=$ 6). Heart failure was diagnosed by Framingham criteria (distended neck vein, shortness of breath and rales due to pulmonary oedema, S3, gallop and Jugular reflex). Supporting evidence of heart failure in ECG (IHD, MI and LVH), chest X-ray (cardiomegaly or pulmonary oedema) or echocardiography (systolic or diastolic dysfunction) was also taken into consideration in diagnosing heart failure. Diagnostic criteria of controls were respiratory rate $>40 / \mathrm{min}$ with presence of rhonchi and absence of rales on auscultation and left ventricular ejection fraction $>60 \%$. Patients with acute coronary syndrome, renal failure, anaemia, thyrotoxicosis and age of the patients $>70$ years or $<20$ years were excluded from the study.

Patients who met the enrollment criteria and provided informed written consent were taken in the study. Data pertaining to variables of interest were recorded using a structured questionnaire. Two cardiologists independently reviewed the patients and diagnosed the cases of congestive heart failure and COPD or asthma. The patients of heart failure were grouped according to New York Heart Association functional class into class I, class II, class III, and class IV. On the basis of ejection fraction they were grouped into systolic heart failure (LVEF $<45 \%$ ) and non-systolic heart failure (LVEF > 45\%). With full aseptic precaution $3 \mathrm{ml}$ of venous blood was taken from each subject. Plasma was separated by centrifuging the blood at $3000 \mathrm{rpm}$ for 10 minutes and 1.8 $\mathrm{ml}$ of it was collected in a separate tube for estimation of B-type natriuretic peptide (BNP) level using Micro particle enzyme immune assay (MEIA) principle in AxSYM system. ${ }^{8}$ 12-lead Electrocardiogram was performed to observe any evidence of heart failure. Plain Chest X-ray P/A view to see the evidence of HF. 2D, Mmode and Doppler echocardiography was performed to find the etiology of heart failure and to assess the systolic or diastolic dysfunction. Data were analyzed using SPSS (Statistical Package for Social Sciences) version 11.5. Data presented on categorical scale were compared between the study groups with Chi-square $\left(\chi^{2}\right)$ or Fisher's Exact Probability Test, while the data measured on continuous scale were analysed using Student's t-Test. A cut-off value of plasma BNP $>100 \mathrm{pg} / \mathrm{ml}$ was used to determine its accuracy in diagnosing heart failure against the established diagnosis of heart failure by echocardiography. ${ }^{3,9}$ Level of significance was 0.05 an $\mathrm{p}<0.05$ was considered significant.

\section{Results}

The demographic characteristics of the study subjects demonstrate that approximately $57.7 \%$ of the established cases of heart failure and $64.3 \%$ of the controls were over 50 years of age and the rest $(42.3 \%)$ of the cases and controls $(35.7 \%)$ were 50 or below 50 years of age. More 
than $70 \%$ of both cases and control were male and the rest female with male to female ratio being roughly $3: 1$. The groups were almost identical in terms of both age and $\operatorname{sex}(p=0.482$ and $p=0.814$ respectively) (Table $I)$.

Table I. Demographic characteristics of the study subjects

\begin{tabular}{lccc} 
& \multicolumn{2}{c}{ Group } & \\
$\begin{array}{l}\text { Demographic } \\
\text { characteristic }\end{array}$ & $\begin{array}{c}\text { Case } \\
(\mathrm{n}=78)\end{array}$ & $\begin{array}{c}\text { Control } \\
(\mathrm{n}=42)\end{array}$ & p-vale \\
$\begin{array}{l}\text { Age (years) } \\
=50\end{array}$ & $33(42.3)$ & $15(35.7)$ & 0.482 \\
$>50$ & $45(57.7)$ & $27(64.3)$ & \\
Sex & & & \\
Male & $56(71.8)$ & $31(73.8)$ & 0.814 \\
Female & $22(28.2)$ & $11(26.2)$ & \\
\hline
\end{tabular}

Figures in the parentheses denote corresponding \%. \# Data were analysed using Chi-square $\left(\chi^{2}\right)$.

Distribution of the heart failure patients by NYHA functional class shows that over $60 \%$ of the cases belonged to class-IV followed by $28.2 \%$ to Class-III, $10.3 \%$ to Class-II and only $1.3 \%$ to Class-I (Fig. 1). Nearly $95 \%$ of the cases had plasma BNP $>100 \mathrm{pg} / \mathrm{ml}$, while $90.5 \%$ of the controls exhibited plasma BNP 100 or below $100 \mathrm{pg} / \mathrm{ml}$. The heart failure cases were significantly associated with raised plasma BNP level $(p<0.001)$ (Table II). The mean plasma BNP level of cases was also staggeringly higher compared to that of control $(\mathrm{p}<0.001)$. The plasma BNP was also found to

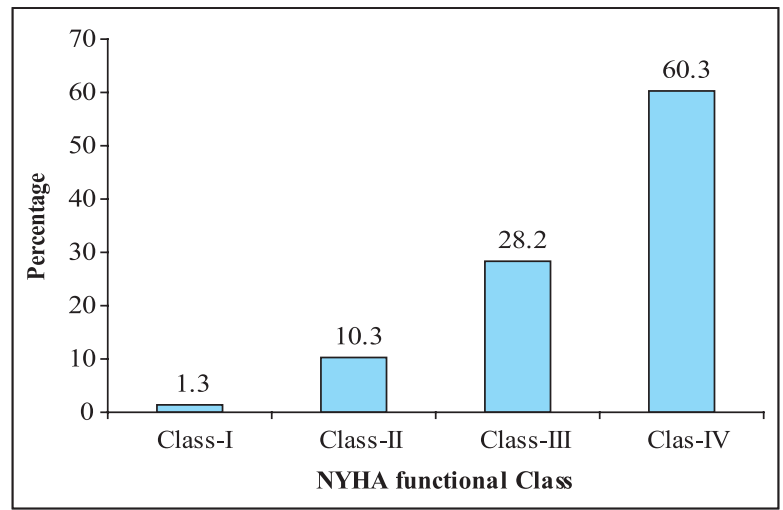

Fig. 1: Distribution of heart failures cases by NYHA functional class

increase significantly with the severity of heart failure classified by NYHA functional class $(\mathrm{p}<0.001)$. The mean plasma BNP levels of Class I, Class II, Class III and Class IV were 119, 149.5, 241.1, $1246.5 \mathrm{pg} / \mathrm{ml}$ respectively $(\mathrm{p}<0.001)$ (Table III \& and Fig 3 ). All the cardinal signs and symptoms of heart failure like dependant oedema, distended neck vein, hepatojugular reflux, rales, S3 gallop, hepatomegaly and PND were significantly higher in patients with plasma BNP $>100$ $\mathrm{pg} / \mathrm{ml}$, than those with plasma BNP 100 or below 100 $\mathrm{pg} / \mathrm{ml}$ and their $\mathrm{p}$ values were $\mathrm{p}<0.001, \mathrm{p}<0.001, \mathrm{p}<$ $0.001, \mathrm{p}<0.001, \mathrm{p}<0.005, \mathrm{p}<0.005$ and $\mathrm{p}<0.001$ respectively (Table IV). Chest X-ray demonstrate that more than $60 \%$ of the patients with plasma BNP $>100$ $\mathrm{pg} / \mathrm{ml}$ had cardiomegaly compared to only $4.7 \%$ of those with plasma BNP 100 or less than $100 \mathrm{pg} / \mathrm{ml}$ (Table VI). Table VII and Fig. 5 demonstrate that mean plasma BNP was observed to be staggeringly high among the systolic heart failure group $(978.38 \mathrm{pg} / \mathrm{ml})$ compared to that among non-systolic heart failure group (390.68 pg/ml) (p $<0.001$ ) (Table VII \& Fig. 5).

Table II. Demographic characteristics of the study subjects.

\begin{tabular}{|lccc|}
$\begin{array}{l}\text { Plasma BNP level } \\
\text { characteristic }\end{array}$ & $\begin{array}{c}\text { Case } \\
(\mathbf{n}=\mathbf{7 8})\end{array}$ & $\begin{array}{c}\text { Control } \\
(\mathbf{n}=\mathbf{4 2})\end{array}$ & p-vale \\
$=100$ & $5(6.4)$ & $38(90.5)$ & $<0.001$ \\
$>1000$ & $73(93.6)$ & $4(9.5)$ & \\
\hline Mean \pm SD & $\mathbf{8 3 5 . 9} \pm \mathbf{1 1 3 . 3}$ & $\mathbf{1 0 9 . 1} \pm \mathbf{6 2 . 5}$ & \\
\hline
\end{tabular}

Figures in the parentheses denote corresponding percentage. \#Data were analysed using Chi-square $\left(\chi^{2}\right)$ Test.

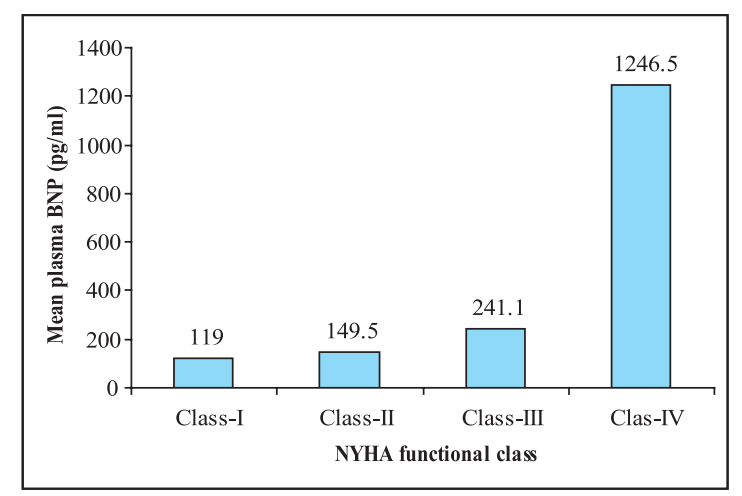

Fig. 2: Plasma BNP level according to severity of heart failure

Table III. Association between plasma BNP and types of heart failure

\begin{tabular}{|lccc|}
\hline Types of heart failure & \multicolumn{2}{c}{ Plasma BNP level $(\mathbf{p g} / \mathbf{m l})$} & p-value \\
& Mean & SD & \\
\hline Systolic $(\mathrm{n}=59)$ & 978.38 & 142.43 & 0.025 \\
Diastolic $(\mathrm{n}=19)$ & 390.68 & 88.95 & \\
\hline
\end{tabular}

\# Data were analysed using Unpaired t-Test and were presented as mean $\pm S D$.

Table IV. Accuracy of plasma BNP in diagnosing heart failure

\begin{tabular}{|c|c|c|c|}
\hline \multirow[t]{2}{*}{ Plasma BNP level (pg/ml) } & \multicolumn{2}{|c|}{ Established diagnosis } & \multirow[t]{2}{*}{ Total } \\
\hline & Heart failure & COPD & \\
\hline$>100$ & 73 & 4 & 77 \\
\hline$=100$ & 5 & 38 & 43 \\
\hline Total & 78 & 42 & 120 \\
\hline
\end{tabular}




\section{Discussion}

This study was undertaken to find out the plasma BNP level in patients suffering from heart failure and to assess the severity of heart failure by measuring B-type natriuretic peptide. About $58 \%$ of the cases were over 50 years of age which is consistent with age distribution of the heart failure patients reported by Rahman. ${ }^{10}$ Heart failures were predominantly caused by ischemic heart disease $(58.9 \%)$ followed by dilated cardiomyopathy (20.6\%), valvular heart disease (10.3\%), hypertensive heart disease $(7.5 \%)$ and shunt anomaly $(2.6 \%)$. Islam ${ }^{11}$ reported a similar finding with the commonest cause of heart failure being ischemic heart disease followed by hypertension and valvular heart disease. In the developed countries as well, the commonest cause of heart failure is ischemic heart disease. The present study revealed that majority of the subjects with plasma B-type natriuretic peptide $>100 \mathrm{pg} / \mathrm{ml}$ had rales and paroxysmal nocturnal dyspnoea followed by oedema, hepatojugular reflux, distended neck vein, hepatomegaly all of which were significantly higher than those with plasma natriuretic peptide $=100 \mathrm{pg} / \mathrm{ml}$. A similar result was found in the study of Maisel et al. ${ }^{3}$ These findings signify that clinical characteristics of heart failure correlates well with consequent rise of plasma BNP.

Cardiomegaly was more frequently observed in patients with BNP level $>100 \mathrm{pg} / \mathrm{ml}$ compared to those with BNP level 100 or $<100 \mathrm{pg} / \mathrm{ml}$. The mean plasma B-type natriuretic peptide level in patients with heart failure was $835.9 \mathrm{pg} / \mathrm{ml}$ and that in patients of COPD and bronchial asthma was $109.1 \mathrm{pg} / \mathrm{ml}$ which was closer to the figures found by Maisel et al. ${ }^{3}$ Similar type of findings were also observed in congestive heart failure patients by Dao et $a l^{12}$, Cowie et $a l^{13}$ and McCullough. ${ }^{9}$ As plasma B-type natriuretic peptide levels were compared among clinical subgroups of heart failure, B-type natriuretic peptide was found to increase with the increase of severity of heart failure from NYHA class I to class IV with significant intergroup differences. Maisel and his associates ${ }^{3}$ also found a gradual increase in plasma B-type natriuretic peptide level from NYHA class I to NYHA class IV. A study done by Wieczorek ${ }^{14}$ demonstrated a direct relation of palsma B-type natriuretic peptide with the severity of heart failure.

In our study three-fourths of cases had systolic heart failure (LVEF $<45 \%$ ) and one-fourth of cases had nonsystolic heart failure (LVEF $>45 \%$ ). The plasma B-type natriuretic peptide level was found to be significantly raised among the systolic heart failure group compared to non-systolic heart failure group which bear consistency with the findings of Iwanaga et all ${ }^{15}$ and Maisel et al. ${ }^{3} \mathrm{On}$ the basis of the empirical cut-off value of plasma BNP
$100 \mathrm{pg} / \mathrm{ml}$ in the diagnosis of heart failure, our study showed that the sensitivity of BNP in correctly diagnosing was $93.6 \%$ and specificity was $90.5 \%$. We also found that the positive predictive value of the test was $94.8 \%$ and the negative predictive value of the test was $88.4 \%$. Our findings were very close to that of Maisel et $a l^{3}$, Wieczorek ${ }^{14}$ and Morrison et al. ${ }^{6}$

Our study showed that the diagnostic accuracy of B-type natriuretic peptide was $92.5 \%$ for differentiating congestive heart failure from other causes of dyspnoea. Maisel et $a l^{3}$ found the diagnostic accuracy which was nearly similar to our result. The result was similar to that found by Morrison et al. ${ }^{6}$ Therefore it can be assumed that the plasma B-type natriuretic peptide not only increases in heart failure patients but also rises gradually as the heart failure progresses to the advanced stages. So it can be an accurate predictor of the presence or absence of heart failure and may also be used for clinical staging of heart failure. B-type natriuretic peptide level is significantly higher in patients with systolic heart failure but it cannot distinguish between systolic and non systolic heart failure.

\section{Conclusion}

B-type natriuretic peptide is a rapid and sensitive biomarker for diagnosing heart failure. The plasma BNP level also increases progressively with the severity of heart failure. It is a valid screening test with promising sensitivity, specificity, positive and negative predictive values and diagnostic accuracy. It can play an important role in the diagnosis of heart failure in emergency department. Use of this test, in conjunction with other clinical information may lead to a more accurate initial diagnosis of congestive heart failure. But for a conclusive evidence further study with a large sample size is recommended.

\section{References}

1. Carbajal EV, Deed wam'a PC 2002, "Congestive heart failure' in Current Diagnosis and Treatment in Cardiology. second Edition, Lange Medical Books/Me Graw-Hill, Arizona, pp.217-249.

2. Haque KMHSS, Nazimuddin K, Hossain M 1983, 'Evaluation of risk factors of ischaemic heart disease in hospitalized patients', J Bangladesh Coll Phys Surg, Vol. 1, pp. 11-6.

3. Maisel AS, Krishnaswamy P, Nowak RM, Me Cord James, Hollander JE, Due P, et al 2002, 'Rapid Measurment of B type Natriuretic Peptide in the emergency Diagnosis of heart failure', NEnglJMed, Vol. 347,pp. 161-167.

4. Baggish AL, Cameron R, Anwaruddin S, Chen AA, Krauser DG, et al 2004, A clinical and biochemical critical pathway for the Evaluation of patients with suspected Acute Congestive Heart failure. The pro BNP investigation of dyspnea in emergency department (PRIDE) Algorithm. Crit Pathways in Cardiol, Vol. 3, pp. 171-176. 
5. Rodeheffer RJ 2004, 'Measuring plasma B type natriutritic peptide in heart failure', J Am Coll Cardiol, Vol. 44, pp. 740749.

6. Morrison LK, Harrison A, Krishnaswamy P et al., 2002, 'Utility of rapid B-natriuretic Peptide assay in differentiating congestive heart failure from lung disease in Patients Presenting with dyspnoea', J Am coll cardiol, Vol. 39, pp. 202-209.

7. Krishnaswamy P, Lubien E, Clopton P, Koon J, Kazanegra R, Wanner E et al., 2001, 'Utility of B-natriuretic peptide levels in identifying patients with left ventricular systolic or diastolic dysfunction', Am JMed, Vol. Ill, no.4, pp. 274-9.

8. Axis-Shield Diagnostics 2003, ' Estimation of plasma BNP' In: operation Manual for Ax SYM. BNP, Abbott Laboratories, USA.

9. McCullough PA, Nowak RM, Me cord J 2002, 'B-Type natriuretic Peptide and Clinical Judgment in emergency diagnosis of heart failure. Analysis from breathing not Properly (BNP) Multinational study', Circulation ,Vol. 106, pp. 416-422.

10. Rahman M 1999, Thesis (BSMMU), Left Ventricular diastolic dysfunction in Congestive heart failure due to systemic hypertension, pp. 47.
11. Islam KHQ, Ali MA, Saha GK, Gopi H, Rhaman MS, Rahman AKMM, Saha CK, HAQ SM, 1998, 'Pattern of heart failure in national institute of cardiolvascular diseases (NICVD), Dhaka', Bangladesh Heart Journal, Vol. 13, no.1, pp. 13-20.

12. Dao Q, Krishna swarny P, Kazanegra R, Harrison A, Amirnovin R, Lenert L, Clopton P, Alberto J, Illavin P, Maisel AS 2001, 'Utility of B-type natriuretic peptide in the diagnosis of congestive heart failure in an urgent care setting' , J Am Coll Cardiol, Vol. 37 ,no.2, pp. 379-85.

13. Cowie MR, Struthers AD, Wood DA, Coats AJ, Thompson SG, Poole-Wilson PA, et al 1997, 'Value of natriuretic peptides in assessment of patients with possible new heart failure in primary care', Lancet,Vol. 350,no.9088,pp. 1349-53.

14. Wieczorek SJ et al., 2002 'A rapid B-type natriuretic Peptide assay accurately diagnoses left ventricular dysfunction and heart failure: a multicenter evaluation', Am Heart J, vol. 144, no.5, pp. 834-9.

15. Iwanaga Y, Nishi I, Furuichi S, Noguchi T, Sase K, Kihara Y et al. 2006, 'B-type Natriuretic Peptide strongly reflects diastolic wall stress in Patients with chronic heart failure', J Am Coll Cardiol, Vol 47, pp. 742-748. 